\title{
O processo de apropriação da leitura e da escrita no cotidiano de crianças de camada popular: uma abordagem histórico-cultural
}

\author{
A historical and cultural approach to \\ the learning process of reading and \\ writing in the daily lives of children \\ from a lower social sphere
}

Leila Cristina Borges da SILVA*

RESUMO: O presente texto discute alguns aspectos de minha dissertação de mestrado enfocando o processo inicial de elaboração das questões da pesquisa: como as crianças se apropriam das práticas de leitura e de escrita no cotidiano em que vivem? O referencial teórico da História- Cultural (Chartier, 1996 e Hébrard, 1996) possibilitou entender que as práticas de leitura e de escrita vivenciadas por crianças de camada popular, são mediadas, entre outros fatores, pelas experiências orais e compartilhadas, as quais são vivenciadas por elas dentro ou fora da escola. Desde o processo inicial de elaboração das questões da pesquisa percebi que os relatos das crianças e de suas famílias estavam relacionados a um discurso histórico amplo, acerca da leitura, marcado, também por uma prática religiosa intensa. A pesquisa foi desenvolvida na sala onde atuei como professora, portanto, estive inserida no processo de ensino-aprendizagem e nas relações estabelecidas com as crianças naquelas circunstâncias. Dessa forma, assumi a perspectiva apontada por Certeau (1994) na qual o pesquisador, "mergulhado" na realidade pesquisada, reconhece-se a si próprio como estando implicado pelos usos do sujeitos que operam no cotidiano.

Palavras-chave: práticas de leitura e de escrita, história-cultural

ABSTRACT: This study discusses some aspects of my Master's dissertation focusing on the initial process when forming the questions for the research: how do children learn reading and writing in their daily lives? The theoretical referential of Cultural History

\footnotetext{
* Mestre em Educação pela Universidade Estadual de Campinas e membro do grupo de pesquisa: AULA - Trabalho Docente na Formação inicial. Professora da Rede Municipal de Ensino de Campinas. Email: leilacbsilva@bol.com.br.
}

Olhar de professor, Ponta Grossa, 8(2): 147-162, 2005. 
(Chartier, 1996 and Hëbrard, 1996) allowed me to understand that reading and writing practices lived by children coming from a lower social sphere are mediated, among other factors, by oral and shared experiences lived by them in or out of school. From the initial stages of preparing the questions for the research, I noticed that the accounts given by the children and their families were related to an ample historical discourse on reading, also marked by an intense religious practice. The research was developed in the classroom where I worked as a teacher and I was therefore part of the teaching-learning process and part of the relationships that were established with the children under those circumstances. In this way, I used the perspective pointed out by Certeau (1994), where the researcher, 'plunging' into the reality being studied, sees himself/herself involved in the uses of the subjects in their daily lives.

Key words: reading and writing practices, cultural history

\section{OSCAMINHOS DALEITURAEDA ESCRITA}

"O capítulo que começamos e ainda não sabemos que história vamos contar é como a encruzilhada que superamos ao sair do convento e não sabemos se nos vai colocar diante de um dragão, um exército bárbaro, uma ilha encantada, um novo amor (...). Aqui está ó futuro, saltei na sela de seu cavalo (...)"

\section{Ítalo Calvino}

O trabalho desenvolvido na Rede Municipal de Ensino de Campinas, como professora de Educação Infantil de uma escola de periferia, desencadeou algumas inquietações que me levaram a buscar respostas mais precisas acerca das práticas de leitura e de escrita nas quais as crianças estavam inseridas. Como professora, fui surpreendida pelo novo: aqui está ó futuro, saltei na sela de seu cavalo.
As indagações foram sendo construídas no cotidiano de minha prática pedagógica, partindo inicialmente das vozes das crianças e de suas famílias - daí sua força sedutora: compreender as práticas de leitura e escrita, por meio de seus relatos, é também uma maneira possível de compreender meu papel como professora-pesquisadora inserida no mencionado contexto de ensino e de aprendizagem.

Sendo assim, no processo de pesquisa surgiram algumas possibilidades de redefinir, por meio da interlocução, os conceitos e os "pré-conceitos" sobre as práticas de leitura e de escrita vivenciadas pelas crianças. Busquei também, no decorrer do processo, compreender os valores sociais e culturais que permeiam essas práticas, reservando-me o direito de olhar para o meu próprio papel de professora: "de ser e de estar neste movimento",

Sobre isso, Arendt (1993, p. 30-40) 
discute o termo compreensão. Para ela, a compreensão configura-se como um processo complexo, que jamais produz resultados inequívocos, distinguindo-se da informação incorreta e do conhecimento científico. Segundo a autora, a compreensão é ainda uma maneira "de ser e de estar neste mundo" e tem como resultado o significado que produzimos em nosso próprio processo de vida, na medida em que tentamos nos reconciliar com o que fazemos e com o que sofremos.

Ao elaborar as questões da pesquisa busquei reconciliar-me com o que faço, com o que sofro, conferindo significado ao conhecimento que tenho como professora e ao conhecimento que têm aqueles que constroem comigo as relações de ensino.

Uma postura de ouvir as vozes das crianças e de dialogar com elas inaugurou minha primeira tentativa de reconciliar-me com as práticas de leitura e de escrita. De acordo com Arendt (1993, p. 51):

Assim como em nossas vidas pessoais nossos piores medos e maiores esperanças jamais nos preparam bem para o que de fato acontece -já que no momento em que se dá um evento, até mesmo quando ele é antevisto, tudo muda sem que jamais possamos estar preparados para a inexorável literalidade desse "tudo" (...)

Esse processo de compreensão das práticas de leitura e de escrita vivenciadas pelas crianças foi sendo atravessado por episódios vividos diariamente com elas e com suas famílias, ou melhor, foi sendo definido também em relação a eles. Um caso particular, vivido na escola, logo no início da pesquisa, marcou o processo de elaboração de minhas perguntas sobre as práticas de leitura e de escrita: como as crianças se apropriam das práticas de leitura e de escrita no cotidiano em que vivem?

Observava as crianças brincando pelo parque, correndo, balançando. Algumas crianças sentadas no tanque de areia olhavam-me, mexiam na areia, contavam casos. Aproximou-se de mim uma menina, olhou-me um pouco, segurou em minhas mãos e perguntou-me em tom baixo, lento e desconfiado:

- Professora, por que você não gosta que te chama de tia?

Certa da resposta, não hesitei em dizer:

- O que eu sou? Sua professora ou sua tia?

Ela riu e respondeu:

- Professora você não é, você não dá lição.

Pensando estar sendo cobrada por fazer "trabalhos/atividades" para e com eles, e atribuindo um caráter mais gostoso (pelo menos para mim) à lição, respondi:

- As atividades que a gente faz aqui na escola, as histórias que a gente lê, a maquete da casa, os desenhos... Tudo isto, "é lição", é lição de criança pequena. 
- Isto não é lição. Eu queria que você ensinasse lição de verdade. A gente não é desse tamanho [faz gesto indicando alguém menor que ela].

- Como é lição de verdade?

- É de escrever, de passar na lousa para gente copiar, igual da escola do Barnabé ${ }^{1}$ que a minha irmã vai.

Nesse momento, as crianças que estavam próximas a nós e prestavam atenção na conversa riram quando eu disse "qual era a lição para criança pequena". Demonstravam concordar com a colega, pois balançavam a cabeça quando ela falava, como se dissessem: $E$ !

Talvez, se me mantivesse inflexível diante de "verdades" e posições que assumo em relação ao meu papel como professora, não teria a possibilidade de dialogar com as crianças e, conseqüentemente, de dialogar com a prática pedagógica. As vozes dos sujeitos que compartilham comigo as relações de ensino passariam desapercebidas e seriam consideradas menos importantes, diante de tantas atividades "prazerosas" que proponho e que acredito serem mais importantes para elas ${ }^{2}$.

Porém, se um diálogo interminável é construído (neste caso, em relação às práticas de leitura e de escrita), como aponta Arendt (1993, p. 52), se- remos um começo, seremos círculos viciosos, permitiremos a imaginação que nos aproxima do que é aparentemente distante e remoto: "Sem esse tipo de imaginação, que na verdade é compreensão, jamais seríamos capazes de nos orientar no mundo. Ela é a única bússola interna que possuímos. Somos contemporâneos somente até o ponto em que chega nossa compreensão".

A criança, por meio do diálogo construído comigo, tenta compreender seu papel na escola, seu lugar de aluna e meu lugar de professora - que é imediato ao seu próprio lugar. Atribui um sentido para a escola, a qual, na sua visão, é o local onde se aprende a escrever; e atribui também um sentido ao papel da professora, que é o de ensinar a escrita e a leitura. A criança demonstra conhecer a experiência escolarizada da leitura, mesmo sem estar vivenciando-a, na prática organizada por mim.

A experiência escolarizada a que me refiro seria marcada por atividades tais como: a cópia mencionada pela criança, como exemplo do que seja lição: - Isto não é lição - ou, ainda, a idéia de uma "idade certa" para se aprender tais tarefas, uma "iniciação determinada previamente com autorização da escola”.

\footnotetext{
${ }^{1}$ Refere-se a uma escola de ensino fundamental.

${ }^{2}$ Convém ressaltar que o objetivo do texto é narrar os modos pelos quais minhas indagações em relação às trajetórias de leitura e escrita foram sendo constituídas. Portanto, não pretendo fazer uma análise minuciosa dos episódios vividos na escola, tal como fiz na dissertação de mestrado.
} 
Seria convincente dizermos que o conceito (presente na fala da criança) em relação ao papel da escola, no processo de apropriação da escrita e da leitura, é simplesmente a expressão de uma prática tradicional de alfabetização?

Arendt ressalta que o modo como os clichês se instauram em nossa linguagem cotidiana além de nos privar da faculdade da fala, nos remetem a um processo de doutrinação. Tal processo, imbricado de afirmações convincentes, destrói por completo o processo de compreensão, visto que tais afirmações tornam-se inquestionáveis, como se fossem tão confiáveis quanto os fatos e os números.

Segundo a autora, ainda que muitos, em uma postura como essa, tenham a boa intenção e a finalidade de elevar a opinião pública, acabam por promover uma luta totalitária contra a compreensão. De acordo com essa perspectiva, a fala da criança mencionada anteriormente não poderá ser vista como uma compreensão equivocada, ou menos importante diante do discurso acadêmico. Se assim agirmos, estaremos instaurando uma luta totalitária contra a compreensão.

Por meio da fala da criança, somos colocados diante da discussão acerca do papel da escola em relação à apropriação da leitura e da escrita e também diante do desejo dela em aprender tais práticas.

\section{ALGUMAS CONSIDERAÇÕES METODOLÓGICAS}

"Ninguém aprende o ofício de conhecedor limitando-se às regras preexistentes. Nesse tipo de conhecimento entram em jogo (diz-se normalmente) elementos imponderáveis: faro, golpe de vista, intuição”.

Carlo Ginzburg

No percurso do trabalho procurei construir uma relação com alguns pressupostos metodológicos da História Oral, em especial os que se referem ao relato e à memória dos sujeitos. Thompson (1992, p. 196), ao discorrer sobre as contribuições e viabilidades de um trabalho que contempla a História Oral, ressalta: "Em suma estamos lidando com fonte vivas que, exatamente por serem vivas, são capazes, à diferença das pedras com inscrições e das pilhas de papel, de trabalhar conosco num processo bidirecional."

Partindo inicialmente de minhas experiências como professora-pesquisadora, busquei construir um diálogo com as crianças e com suas famílias, o qual revelou alguns suportes de leitura que circulavam nas suas casas. Por meio do diálogo, pude perceber também os modos como a leitura era feita, ou por quem era feita.

A comunidade para a qual dirigi o meu olhar é desprivilegiada social-

Olhar de professor, Ponta Grossa, 8(2): 147-162, 2005. 
mente, reconhecida muitas vezes como aquela que não lê (o que o cânone escolar define como leitura), ou ainda como aquela que não tem interesse ou até mesmo "capacidade" para colaborar/trabalhar junto com a escola.

Ao lançar mão dos pressupostos teórico-metodológicos da HistóriaOral, pude entender que a voz daquele que narra possibilita uma outra versão da história, mais verdadeira e democrática, porque é vivida por eles, compartilhada com seus "iguais". Sendo assim, a História Oral tem por finalidade contribuir na elaboração de uma memória mais democrática do passado, pois, a história que é contada está a cargo das comunidades, como afirma Thompson (1992, p. 18):

Esse tipo de projeto propicia, sobretudo fazer da história uma atividade mais democrática, a cargo das próprias comunidades, já que permite construir a história a partir das próprias palavras daqueles que vivenciaram e participaram de um determinado período, mediante suas referências e também seu imaginário.

O referido autor (1992, p.137) comenta que a evidência oral pode conseguir algo fundamental para a história, já que ela, transformando os "objetos" em "sujeitos" da pesquisa, afasta-se de uma descrição "defeituosa" dos sujeitos, ou ainda de projeções da experiência do próprio historiador.

Para Thompson, toda fonte é moldada e filtrada a partir de um viés sobre o qual o historiador não está seguro, por isso convém que o pesquisador busque consistência interna confrontando as evidências com um contexto social amplo. Essa atividade exige uma grande sensibilidade por parte do pesquisador, de modo que ele esteja atento às pressões sociais relacionadas ao problema de pesquisa.

Bourdieu (1996), acerca das infidelidades em relação às recordações de infância ${ }^{3}$, relata que as pessoas são pouco seguras em razão daquilo que chamam de efeito de legitimidade, pois, ao perguntarmos a alguém o que lê, em geral se entende o que lê e merece ser declarado.

Sobre isso Pompougnac (1997, p. 33 ) ressalta também que as representações do ato de ler na infância são permeadas pelos discursos que prescrevem, regulam, exortam a chamada "boa leitura". Neste caso, mediadas pelas situações de sala de aula, nas quais puderam relatar suas práticas de leitura e perceber que as mesmas foram "autorizadas", as crianças/famílias declararam com maior segurança suas vivências de leitura, inclusive materializando-as por meio dos suportes que foram sendo trazidos.

Thompson(1992, p. 254) relata que o trabalho com História Oral requer

${ }^{3}$ Tendo em vista o modelo escolar que normalmente exclui determinadas práticas de leitura. 
do pesquisador algumas qualidades essenciais: "interesse e respeito pelos outros como pessoas e flexibilidade nas reações em relação a eles, capacidade de demonstrar compreensão e simpatia pela opinião deles, e, acima de tudo disposição para ficar calado e escutar".

Guedes-Pinto (2000) também demonstrou em seus estudos que é possível e viável estabelecer uma relação de cooperação entre o pesquisador e os sujeitos da pesquisa. Sobre isso, Thompson (1992, p.217) acrescenta:

Deles nos vem não apenas um estímulo intelectual, mas, às vezes, por ingressar na vida de outras pessoas, uma experiência humana, profunda e comovente. E podem realizar em qualquer lugar pois toda comunidade carrega dentro de si uma história multifacetada de trabalho, vida familiar e relações sociais à espera de alguém que as traga para fora.

Busquei olhar para os relatos dos sujeitos envolvidos neste trabalho, considerando suas respectivas memórias acerca da leitura. Propus olhar as práticas de leitura dentro de um contexto social mais amplo, que é permeado pelos valores sociais e culturais de uma comunidade específica, podendo, dessa maneira, manter viva a história daqueles que estão envolvidos em tal processo.

Como professora-pesquisadora, aproximei-me dos sujeitos qualificados como "afastados do centro" (devido ao fato de morarem na periferia de Campinas) e tomei-os como "operadores" e narradores - procurando compreender a lógica utilizada pelas crianças e por suas famílias na organização de suas "operações táticas", no processo de apropriação da leitura e da escrita, de acordo com Certeau (1994).

Entendo que esse ingresso possibilitou a compreensão dos modos pelos quais meu papel como professora e pesquisadora estava implicado pelos usos dos sujeitos, ou, como diria Certeau (1994), pelos usos dos sujeitos ordinários, visto que estava "mergulhada" no processo de ensino-aprendizagem e nas relações estabelecidas naquelas circunstâncias.

Ao longo de meu convívio com aquela comunidade escolar, percebi que nem todos os sujeitos se reconheciam nas representações ditas “oficiais". Sobre isso, Certeau (1985), ao falar sobre os diferentes pontos a serem considerados nas análises das práticas cotidianas, destaca que o aspecto ético é essencial. Tal aspecto compreende o fato de que as práticas cotidianas constituem uma maneira de o sujeito não se enquadrar à ordem tal como ela se impõe. $O$ aspecto ético existe na medida em que não se obedece a lei dos fatos, portan-to ele é a recusa à identificação preconcebida, ele é o abrir de um espaço, uma vontade histórica de existir.

Assim, empreendi um esforço para compreender como as práticas cotidianas são constituídas como "defesas para a vida". A cultura é insepa- 
rável da luta, da guerra: "E quanto mais fraco se é, mais deve ser malicioso. Ou seja, quanto mais fraco se é, mais necessário se torna ser inteligente" (CERTEAU, 1985, p. 8).

Em sua pesquisa sobre a cultura (em especial sobre os sistemas de representação como a mitologia e comportamentos rituais), Certeau ressalta a necessidade de olhar para um ponto fundamental: a maneira de pôr em prática pelos sujeitos. Para o autor, há um modo particular pelo qual o sujeito apropria-se de tais representações: a re-invenção.

É olhar para o que Certeau (1994, p. 32) denomina artes de dizer, teoria do relato "porque o relato é a língua das operações, abre um teatro de legitimidade para ações efetivas". Logo, não deve ser o discurso ou a citação indefinida do outro, visto que o enfoque da cultura começa quando o homem ordinário se torna o narrador, quando define seu lugar (comum) do discurso e o espaço (anônimo) de seu desenvolvimento.

Finalmente, há aqui um comprometimento com o combate à presunção que leva a filosofia a fazer, "como se" ela desse sentido ao uso ordinário e supusesse para si mesma um lugar próprio de onde pensar o cotidiano. De acordo com Certeau (1994, p.152): "Noutras palavras será um relato. Será a própria arte de fazer e de pensar, pode ser ao mesmo tempo a prática e a teoria desta arte".

\section{AHISTÓRIA-CULTURAL: DIALOGANDO COM AS REPRE- SENTAÇÕES ESCOLARES}

Baseando-me nos estudos de Chartier (1999), olhei para as trajetórias de leitura e de escrita das crianças considerando-as inseridas no campo das práticas sociais e no campo da história, a qual é reconstruída e reinterpretada pelos sujeitos nela envolvidos. Sujeitos esses que compartilham determinadas normas e valores que organizam as práticas de leitura e de escrita, impedindo assim que as mesmas fiquem restritas a uma coleção de casos indefinidos.

A pesquisa está inscrita em um espaço que valoriza a história social e cultural da leitura, que põe luz nos gestos e representações que foram sendo construídos historicamente, assim como a idéia expressa anteriormente pela criança, que traz em seu bojo um processo histórico permeado por valores e ritos. Volto à fala da criança: - É de escrever, de passar na lousa para gente copiar, igual da escola do Barnabé que a minha irmã vai.

Convém ressaltar também um outro aspecto presente na fala da criança: a relação da irmã com a escrita é algo compartilhado naquela família. $\mathrm{O}$ modo pelo qual a criança define a experiência de escrita de sua irmã, citando-a como atividade escolar, deixa vestígios de que essa prática é esten- 
dida fora da escola. Ou seja, as práticas escolares mantêm "relação com as que se dão fora da escola e viceversa".

Certo dia, uma criança trouxe para escola a fotografia de seu aniversário de cinco anos, em virtude de um trabalho que realizamos sobre suas histórias de vida. Contou para a turma quem eram as pessoas da fotografia. Uma das crianças presentes na imagem da foto - a mais velha (oito ou nove anos), foi apresentada por ela como sendo a amiga que brinca junto de escolinha e que ocupa o papel de professora. Perguntei-lhe sobre o motivo de tal criança ter sido escolhida "professora": Porque ela é grande.

A experiência das crianças em relação à leitura e escrita demonstrou ir além dos muros escolares, porém mantendo, em ambos os casos, uma relação com a prática escolar. Sobre isso, Cavallo e Chartier (1998, p. 8) comentam:

Para cada uma das "comunidades de interpretação" assim identificadas, a relação com o escrito efetua-se com técnicas, gestos e maneiras de ser. A relação com a leitura não é apenas uma operação intelectual abstrata: ela é o uso do corpo, inscrição dentro de uma espaço, relação consigo mesma ou com os outros.

Como ocorre a relação com o es- crito nas diferentes comunidades de interpretação, com suas técnicas, gestos e maneiras de ser? Temos a questão: como as crianças de camada popular estão inscritas na prática da leitura? Em quais suportes essas práticas têm se materializado?

Para formular respostas a essas questões, considerei como ponto de partida as falas das famílias sobre os treinos preparatórios tradicionalmente destinados a introduzir as crianças no processo de apropriação da escrita e da leitura. Não citarei todos os relatos, porém, convém mencionar que, ao falarem sobre suas expectativas em relação à escola, os pais/família referem-se com frequiência a tal introdução. Relatam experiências escolares de seus filhos mais velhos, sejam elas bem ou mal sucedidas. Mães que não dominam a "tecnologia do ler" comentam sobre o revezamento entre irmãos, no papel de ensinar.

Em uma outra ocasião, uma das mães contou-me que não sabe ler nem escrever, e relatou suas experiências mal sucedidas na escola. Atualmente, trabalha em um condomínio nobre, em um bairro de classe média alta da cidade de Campinas. Disse-me que várias revistas (citou a Veja e algumas revistas estrangeiras) são descartadas pelos moradores após serem lidas e que, mesmo sem saber ler, costuma trazê-las para casa, para que as crianças façam uso desses suportes escritos.

Sobre isto, Castanheira (1992) afir-

Olhar de professor, Ponta Grossa, 8(2): 147-162, $2005 . \overline{155}$ 
ma que a tentativa de garantir o aprendizado da leitura e escrita ocorre em função do valor cultural dessas práticas no contexto ao qual nos referimos. O fato de algumas mães não dominarem a leitura não as impede de reconhecer o valor cultural de tal prática.

É possível relativizarmos a lógica dos que acreditam na inacessibilidade de diferentes suportes de leitura pelas crianças de camada popular devido à falta de recursos financeiros. Parte das famílias com as quais trabalhei e ainda trabalho não se apropriou do código da escrita, porém elas criam mecanismos de acesso aos suportes materiais de leitura para seus filhos.

Certeau (1994), ao explicitar a tentativa dos mais fracos para se manterem no sistema, ou para tirarem partido dos "fortes", nos leva a acreditar também em uma "não perpetuação" da exclusão social em relação às práticas de leitura e escrita, visto que eles se apropriam da leitura e da escrita de diferentes maneiras, as quais, algumas vezes, não são legitimadas nos âmbitos escolares.

Em relação aos diferentes modos de apropriação do escrito, é possível enfocarmos a singularidade que permeia as representações de leitura e escrita propostas por Chartier (1999). Para o autor, conforme as tradições religiosas, intelectuais ou pertinências sociais, desenvolve-se uma multiplicidade de abordagens da leitura. Essas abordagens não são in- finitas, uma vez que elas estão inscritas no interior de normas e modelos que organizam as práticas: "Até o infinito, não. Ler, leitura, essas palavras armam ciladas. (...) há esta multiplicidade de modelos, práticas, de competências, portanto há uma tensão".

Chartier (1999, p. 154) ressalta que para cada uma das leituras, em cada circunstância, o leitor é singular. Todavia, suas leituras são atravessadas por aquilo que faz com que ele seja semelhante a todos aqueles que pertencem à mesma comunidade. Daí que um livro não existe sem o leitor: “(...) pode existir como objeto, mas, sem leitor, o texto do qual ele é portador é apenas virtual. Será que o mundo do texto existe quando não há ninguém para dele se apossar, para dele fazer uso, para inscrevê-lo na memória ou transformá-lo em experiência?"

O reconhecimento da singularidade dos leitores favorece um outro olhar em relação às práticas de leitura e escrita: elas não são mais homogeneizadas, visto que damos visibilidade a uma heterogeneidade de suportes que estão em circulação.

Guedes-Pinto (2000,p. 120) afirma que o sistema educacional e a universidade normalmente desconsideram a heterogeneidade presente na circulação e no consumo da escrita, desqualificando o que parece estar fora do modelo escolar. Nesse sentido, este estudo procurou contemplar a necessidade apontada pela autora: valorizar os diferentes suportes de 
modo que todos eles sejam legitimados como leitura.

De acordo com Guedes-Pinto (2000 p. 225) “o que está em foco é a convivência e o contato com os diferentes estilos de texto possiveis, buscando sempre a ampliação do repertório".

Considerando os diferentes estilos de textos que circulam entre meus alunos, observei em minha prática pedagógica que as experiências das crianças em relação às práticas de leitura e de escrita são diferentes daquilo que eu imaginava, destacando-se entre elas os materiais religiosos (Bíblia, periódicos com textos bíblicos, livros de histórias bíblicas para as crianças, folhetos de hinos etc.). Esses suportes chamam a atenção pela freqüência com que são relatados em aula, sendo que esses relatos apontam para um alto consumo e circulação em suas casas.

Em outras situações vivenciadas por mim na escola, as crianças relatam aspectos sobre a circulação e consumo da escrita em outros suportes: gibis, livros didáticos, cartilhas, livros de literatura infantil etc.

Como mencionei anteriormente, havia solicitado às crianças que trouxessem para a escola fotos de situações vividas em suas casas. Uma fo- tografia de aniversário (citada há pouco) acabou por revelar brincadeiras de escolinha orientada pela criança mais velha: a professora. Outra fotografia que chamou a atenção é a de uma criança em pé, na sala de sua casa, com uma Bíblia na mão.

Ao solicitar à avó que falasse um pouco da fotografia para mim, ela narra suas experiências religiosas, nas quais costuma levar com freqüência seu neto: ensaio de cantos, pregação da "palavra" (feita pelo próprio garoto de seis anos em casa), narração de trechos bíblicos decorados pelos participantes, são práticas de leitura vivenciadas nessa família ${ }^{4}$.

Problematizei o fato de que normalmente a escola desconsidera as experiências religiosas das crianças em relação à leitura/escrita, enfocando apenas o livro escolar, autorizado e legitimado pela instituição. Não teria a Bíblia o "fantástico", tão procurado pelas crianças nas escolhas de suas leituras? Não seria divertido e encantador para elas saberem que Sansão obtinha tamanha força através de seus cabelos compridos? Ou ainda, que Jonas foi engolido por uma baleia? Ou que Deus deixou o arco-íris como um sinal de aliança e amor aos homens?

O livro de Sansão ${ }^{5}$ foi trazido por

\footnotetext{
${ }^{4}$ Outras situações vivenciadas em nossa turma demonstraram-me a familiaridade de algumas crianças com uma prática religiosa da leitura, tais situações são detalhadas na dissertação de mestrado: Práticas de leitura na infância: do limite à transgressão. Campinas: Faculdade de Educação, Unicamp, 2004.

5 Pertencente a uma coleção de: "Aventuras Bíblicas para Crianças".
} 
uma menina e lido por mim. Todos da turma ficaram atentos e maravilhados durante a leitura da história. Após a leitura, um comentário aponta o consumo e a circulação desse estilo de texto: Minha mãe já leu dos filistaus. ${ }^{6}$

No outro dia, comentei com a mãe de um aluno: Ele me disse que você lê a Bíblia pra ele.

A mãe confirma:

- Leio, leio sempre.

No dia seguinte, a mesma criança leva para escola a Bíblia de bolso que tem em casa.

O fato de a criança levar a Bíblia, ou "Aventuras Bíblicas para Crianças", demonstra que as práticas de leitura efetivamente vividas por elas são "assumidas" quando encontram espaço para tal, quando são reconhecidas dentro da instituição como leitura.

Recusando os rótulos e as categorias sobre os tipos de texto e leitura, Guedes-Pinto (2000, p. 173) afirma: "A meu ver, o que define se a professora é uma leitora escolar não é o tipo de texto que lê, mas sim a maneira como se apropria dele, a prática e os usos que faz desta leitura".

Nas leituras religiosas residem também outras possibilidades de estudo apontadas por Cavallo e Chartier (1998), na medida em que as igrejas se esforçam para transformar os cristãos em leitores, o que faz com que a leitura torne-se, em sua definição espiritual e piedosa, inteiramente comandada pela relação com Deus.

É possível relativizar também a lógica dos que acreditam que é por meio dos "livros escolares" que a criança se apropria da leitura e da escrita, ou ainda, daqueles que desconsideram as práticas de leitura que fazem parte do cotidiano das crianças.

Sobre isso, Chartier (1999), ao recuperar a história da leitura, selecionou materiais iconográficos, alguns dos quais alguns têm como centro a questão da leitura mediada pela religiosidade. É o caso, por exemplo, da obra Na Madone du Magnificat, de Botticelli: $\mathrm{O}$ ato da escrita em um dos textos mais cantados da tradição cristã. O livro aberto de cuidadosa caligrafia, ricamente encadernado, dourado nas laterais, traz à memória, mais do que à leitura do espectador, o canto de louvor de Maria: Magnificat anima mea Dominum(Minha alma exalta o Senhor). Sandro Botticeli. Madone du Magnificat (detalhe) cerca de1482-1498. Florence, Museu degli Uffizi. ${ }^{7}$

Ainda sobre a questão da leitura como uma prática religiosa Chartier (1999, p. 140) comenta a pintura de Henri Valkenberg ${ }^{8}$ :

Em um país protestante, no séc.

\footnotetext{
${ }^{6}$ A criança quer dizer: filisteus.

${ }^{7}$ Chartier (1999: p. 6).

8 Diamanche après-midi dans I arrière pays, 1883.
} 
XIX, uma representação ideal da leitura bíblica. Frente a frente, $o$ pai da família, que reuniu em torno de si todos os parentes, e o pastor que explica o texto sagrado.(...) Cada um na reunião recebe a palavra divina, lida ou ouvida. Mesmo a criança, que parece desligar-se familiariza-se, folheando, no chão, aquilo que parece ser uma bíblia ilustrada.

É possível estabelecer uma relação entre os usos históricos da leitura religiosa - apontados pelo autor sejam eles retratados na pintura ou não, com os comentários que as crianças fazem a respeito de suas práticas, ou ainda através dos desenhos que representam situações de leitura.

Depois de uma atividade de desenho em que foi proposto às crianças representarem ocasiões vivenciadas de leitura, uma delas comenta:

- É meu quarto, aqui é minha mãe, ela fecha a porta e fica lendo com a gente, com minha avó também. Ela lêversos.

Fechar a porta; preparar um ambiente que denota tranqüilidade; reunirem-se em torno de um único suporte material para fazer a sua leitura ou para ouvir alguém lendo; permitir um lugar de destaque para a Bíblia; enfocar a criança familiarizando-se com essa prática - modos de ler que deixam rastros de uma leitura como produção histórica, enquanto ato físico, e não como uma atividade intelectual abstrata, como mencionei anteriormente.

No processo da pesquisa propusme a recuperar a história das práticas de leitura de crianças pequenas, junto a suas famílias, de modo a perceber os vestígios que nos conduzem a refletir sobre as atitudes do leitor, sobre a leitura também como atividade física. ${ }^{9}$ Sendo assim, pude perceber o modo pelo qual as práticas de leitura e de escrita de crianças pequenas junto às suas famílias possuem estreitas conexões com a construção histórica de tais atividades. Os modos de apropriação e representação dessas práticas estão circunscritos a um contexto mais amplo de produção, no qual a leitura é praticada como atividade corporal, e não unicamente intelectual e abstrata.

Para finalizar este texto, gostaria de relatar um episódio que traz à tona um discurso comum, tanto nas escolas quanto nos estudos atuais: formar leitores, desenvolver o gosto/prazer pela leitura. Problematizo o fato do como temos possibilitado tal aspecto, e como as crianças possibilitam a si próprias esse gosto/prazer. Esse episódio demonstrou-me algumas das táticas que as crianças utilizam nos “espaços e tempos" destinados às atividades de leitura na escola.

Trabalhei na biblioteca da escola no período contrário ao que era professora. Dentre as atividades desen-

${ }^{9}$ De acordo com Fraisse (1997). 
volvidas nesse espaço, tínhamos o empréstimo de livros às diversas turmas. Cada turma dispunha de aproximadamente cinqüenta minutos para fazer o empréstimo. Geralmente as salas possuem em média trinta crianças, que são divididas em grupos de cinco (já que o espaço físico da biblioteca é pequeno) na hora do empréstimo. Isso significa que cada grupo tinha aproximadamente oito/nove minutos para escolher seus livros. Procurávamos, como professoras evitar a inflexibilidade em relação à duração das atividades, uma vez que geralmente havia atrasos. Porém, para fins de organização (que sabemos, são necessários), cada professor “definia" em média o tempo que a atividade podia durar. Só que esse "cálculo/ previsão" pode não funcionar diante da diversidade de leitores que temos, como mostram os diálogos a seguir.

Há leitores tão rápidos em suas escolhas. Chegam decididos:

- Tem da Chaupezinho Vermelho?

Há quem vem à procura de novidades:

- Qual que é o mais legal de todos?

Mostro algum livro de que gosto muito, como por exemplo "A Casa Sonolenta". Algumas crianças pedem para eu ler. Leio e, após, pergunto:

- Vai levar esse?

- Não. Tem outro que é mais legal?

Mostro vários livros interessantes...

- Vai levar? Pergunto.
- Não.

E assim ficava eu observando aqueles leitores que não se decidiam, ou não queriam decidir. Eles queriam ficar ali, na biblioteca. Nesse momento, entra na biblioteca um menino, em um dos primeiros grupos da sua sala. Eu sabia que a turma da qual o garoto faz parte recebe orientação da professora para que não demorar nas escolhas dos livros. Pois não foi isso o que ele fez. Ficou lá. Folheava os livros, perguntava-me o título, mudava de opinião acerca do que tinha escolhido. Entrava um outro grupo. E o garoto? Lá continuava.

Logo aparece seu colega de sala. Mas, o que esse colega veio fazer? Será que veio a pedido da professora chamar seu amigo? Também. E o que faria, além disso?

Primeiro: o recado dado pelo colega, em tom de voz ríspido:

- Você não vai mais levar livrinho. Nem adianta pegar porque a professora falou que você tá demorando. Nossa como você demora!

O que me chamou a atenção nesse momento, é que o menino que veio até a biblioteca dar o recado da professora à outra criança, não volta para a sala. Permanece dando bronca no colega. Só que enquanto dava a bronca, ele observava os livros, caminhando até as prateleiras. O menino teve duas atitudes concomitantemente: dava a bronca e folheava os livros.

- Vamos a professora tá chamando. Falava enquanto olhava para os livros, e chega até a fazer comentári- 
os com o colega sobre o livro que estava vendo.

Eu pergunto:

- Você veio chamar o seu colega? Não vai voltar para sala?

- É que eu tô esperando ele.

Assim, os dois ficam na biblioteca, em uma certa cumplicidade. O leitor indeciso e o leitor que aproveita a ocasião para utilizar-se um pouco mais do espaço da biblioteca. Quando o leitor "indeciso" faz sua escolha, ambos retornam juntos para a sala.

\section{RETOMANDO O CAMINHO DA PESQUISA}

A tentativa de contribuir para que as histórias das práticas de ler e de escrever pudessem ser relatadas pelos próprios leitores, pela comunidade focalizada, de modo que os sentidos produzidos por eles pudessem alcançar visibilidade a partir de seus depoimentos, foi o meu principal propósito na realização da pesquisa ora relatada.

Como professora-pesquisadora, empreendi um esforço para compreender as maneiras como as crianças servem-se dos sistemas de representação da leitura, como entendem e reelaboram suas vivências ao desdobrarem o tempo e o espaço da leitura na escola, perambulando entre o limite e a transgressão das práticas.

Para Certeau (1994), a ocasião não é criada, é aproveitada. Pela pesquisa ora relatada, pude comprovar que isso de fato acontece: os sujeitos, em suas práticas de leitura, não criam a ocasião, aproveitam-na. A partir de então, pude (re) elaborar as questões da pesquisa, abrindo um espaço para apreender a diversidade de práticas e táticas de leitura existentes no cotidiano das crianças de camada populares.

Desse modo, pude perceber que as crianças respondem à forma de organização escolar, elas não são passivas diante de nossas escolhas, de nossas imposições. A organização do tempo escolar da leitura, por exemplo, foi cronometrado. Calculado. Tempo para ler. Espaço para ler. Passo-a-passo, nós organizamos cada momento. Mas esse tempo foi reorganizado pelas crianças. Foi burlado. $\mathrm{O}$ fato fezme perceber que, no ato de burlar, a prática da leitura alcança sua inventividade e singularidade.

\section{REFERÊNCIAS}

ARENDT, H. A dignidade da política. Rio de Janeiro: Relume-Dumará, 1993.

BOURDIEU, P. A leitura: uma prática cultural. Debate entre Pierre Bourdieu e Roger Chartier. In: CHARTIER, Roger (Org.). Práticas da leitura. São Paulo: Estação Liberdade, 1996.

CASTANHEIRA, M. L. Da escrita no cotidiano à escrita escolar: Leitura, Teoria e Prática. v. 11, n 20, dez: 1992.

CALVINO, Í. O cavaleiro inexistente. São Paulo: Companhia das Letras. 1993.

CAVALLO, GUGLIEMO \& CHARTEIR. Introdução. In: História da 
leitura no mundo ocidental. São Paulo: Ática, 1998.

CERTEAU, M. A Invenção do cotidiano1: artes de fazer. Petrópolis: Vozes, 1994.

CHARTIER, A. HEBRÁRD, J. Discursos sobre a leitura. São Paulo: Ática. 1995.

CHARTIER, R. (Org.). Práticas da leitura. São Paulo: Estação Liberdade, 1996.

. A aventura do livro: do leitor ao navegador. São Paulo: UNESP, 1999.

FRAISSE, E. et al. Representações e imagens da leitura. São Paulo: Ática.

GUEDES, P. A. L. Rememorando as trajetórias da professora alfabetizadora: a leitura como prática constitutiva de sua identidade e formação profissionais. Tese (D Doutorado). 2000. Universidade Estadual de Campinas. 2000.

GINZBURG, C. O queijo e os vermes: o cotidiano e as idéias de um moleiro perseguido pela Inquisição. São Paulo: Companhia das Letras, 1987.

GINZBURG, C. Sinais: raízes de um paradigma indiciário. In: GINZBURG, C. Mitos Emblemas e Sinais. São Paulo: Companhia das Letras, 1999.

HÉBRARD, J. O autodidatismo exemplar: como Jamerey Duval aprendeu a ler? In: CHARTIER, R. (Org.). Práticas da leitura. São Paulo: Estação Liberdade, 1996.

POMPOUGNAC, J. C. Relatos de Aprendizado. In: FRAISSE, E. et al. Representações e imagens da leitura. São Paulo: Ática, 1997.

THOMPSON, P. A voz do passado: história oral. Rio de Janeiro. Paz e Terra, 1992.
VYGOTSKY, L. S. A formação social da mente. São Paulo: Martins Fontes, 1984.

Encaminhado em: 07/08/05

Aceito em: 26/11/05 